
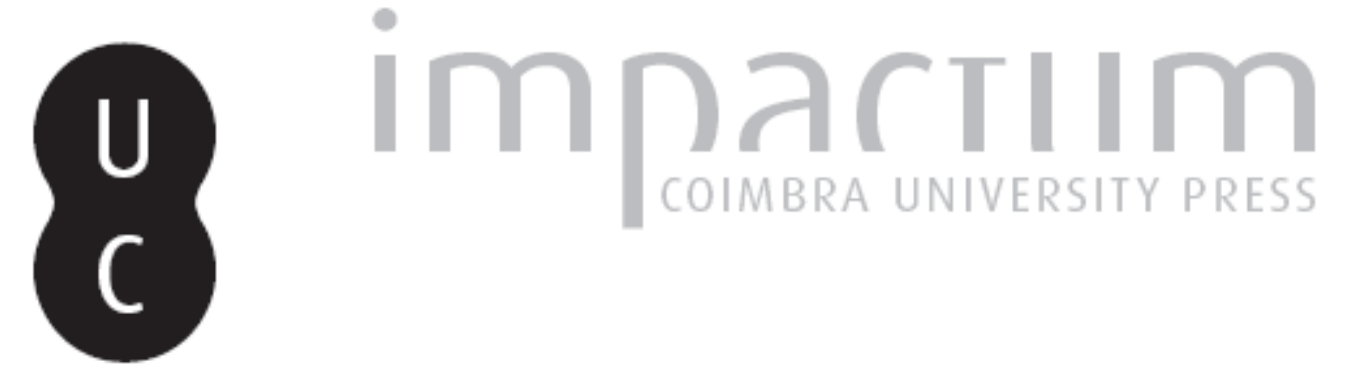

Do tempo e dos trabalhos: a agricultura portuguesa no século XVII

Autor(es): $\quad$ Magalhães, Joaquim Romero

Publicado por: Instituto de História Económica e Social, Faculdade de Letras da Universidade de Coimbra

URL persistente:

URl:http://hdl.handle.net/10316.2/9703

DOI:

DOI:http://dx.doi.org/10.14195/0870-4147_41_3

Accessed : $\quad$ 26-Apr-2023 12:01:01

A navegação consulta e descarregamento dos títulos inseridos nas Bibliotecas Digitais UC Digitalis, UC Pombalina e UC Impactum, pressupõem a aceitação plena e sem reservas dos Termos e Condições de Uso destas Bibliotecas Digitais, disponíveis em https://digitalis.uc.pt/pt-pt/termos.

Conforme exposto nos referidos Termos e Condições de Uso, o descarregamento de títulos de acesso restrito requer uma licença válida de autorização devendo o utilizador aceder ao(s) documento(s) a partir de um endereço de IP da instituição detentora da supramencionada licença.

Ao utilizador é apenas permitido o descarregamento para uso pessoal, pelo que o emprego do(s) título(s) descarregado(s) para outro fim, designadamente comercial, carece de autorização do respetivo autor ou editor da obra.

Na medida em que todas as obras da UC Digitalis se encontram protegidas pelo Código do Direito de Autor e Direitos Conexos e demais legislação aplicável, toda a cópia, parcial ou total, deste documento, nos casos em que é legalmente admitida, deverá conter ou fazer-se acompanhar por este aviso.

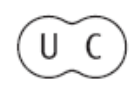





\title{
Do tempo e dos trabalhos: a agricultura portuguesa no século XVII
}

\author{
JoAquim Romero Magalhães \\ Faculdade de Economia \\ jromero@fe.uc.pt
}

\section{Resumo:}

O presente artigo tenta a apreciação de conjunto da agricultura portuguesa no século XVII. Quais as técnicas e os géneros cultivados e os recursos arbóreos mais comuns. A questão é agrária mas também social, pois que muitos impedimentos à modernização têm a ver com as estruturas de domínio que não com o desconhecimento do que poderia ser feito. Tudo se reduzia à manutenção de equilíbrios que se temia quebrar.

\section{Palavras chave:}

Agricultura; Técnicas agrícolas; Milho; Cereais; Equilíbrios sociais.

\section{Abstract:}

This paper tries a joint assessment of the Portuguese agriculture in the 17th century: what techniques were used, what commodities were cultivated, and the most usual arboreal resources. The issue is agricultural, but also social, as many obstacles to modernization have to do with the structures of property, instead of the lack of knowledge of what could be done. Everything was limited to the maintenance of equilibria that were feared to collapse.

\section{Keywords:}

Agriculture; Agricultural techniques; Corn; Cereals; Social equilibria. 
Esforço constante, sem horizontes nem expectativas senão de salvação no outro Mundo. Era assim a vida de quantos no século XVII se dedicavam a fazer a terra e a dar de comer aos que não a tinham ou não a trabalhavam. A terra lá ia retribuindo o que o tempo e o trabalho permitiam. O que não seria nunca muito, nem sequer atingindo muitas vezes o necessário para viver ou apenas para sobreviver. Trabalho nas árvores nos três primeiros meses do ano: tempo de enxertar, de pôr os bacelos e podar as vides; mas também plantar rosas e semear alhos e cebolas em Janeiro; mais podas nas vides, transplantar macieiras e pereiras, pôr estacas de romãs e amoras, limpar as colmeias em Fevereiro; continuar estes trabalhos em Março; semear hortaliça de regadio e lavrar as terras húmidas por Abril; semear melões, cabaças, alfaces e demais verduras por Maio; novos cuidados com as árvores, ceifar trigo e cevada em terras quentes por Junho; continuar com as ceifas, trabalhos nas vides, corte de ervas e colheita de frutos como amêndoas em Julho; preparação dos pousios e semeadura de nabos e couves tardias e preparar os frutos secos e passas e semear o trigo e o linho em Agosto; sementeiras de centeio e cevada em terras húmidas e tremoços em terra quente, semear mais trigo e linho e fazer a vindima por Setembro; novo cuidado com as vides e continuação de sementeiras de trigo, linho, favas e cevada e tratar das árvores que não sentem o frio em Outubro; mais trabalho com as árvores em Novembro; preparo de estercos e novas sementeiras de verduras nas hortas em Dezembro E muito, muitíssimo mais, que para o gado e para as galinhas também há que respeitar o tempo que faz - a chuva ou a estiagem - e os quartos da lua. No calendário agrícola não está previsto descanso para o lavrador. Tudo isto sempre vigiado pelos que vão receber as rendas e os tributos. E que não trabalham.

Trabalhos sempre pensando nesses pagamentos, a fazer quando e onde são devidos. Logo para começar a Igreja leva aos lavradores cerca de dez por cento das suas produções. A Igreja, sempre, às vezes a meias com o comendador do lugar, quando existe. Situação esta que piora a vida das gentes. Porque com o que fica nos celeiros eclesiásticos a colectividade pode contar. Quando há uma carestia, os populares podem valer-se do pão que a igreja tem nas suas reservas, seja para conseguir sobreviver seja para empréstimo de sementes. Porque essa reserva costuma ficar no local onde se recolheu e por caridade ou por crédito funciona quase sempre. Dar de comer a quem tem fome é uma obra de misericórdia. Que os eclesiásticos em geral cumprem. Porém, não há que esperar generosidades tais dos senhores e fidalgos que têm comendas da mão dos reis: os comendadores quando podem vendem o produto das suas rendas e rendimentos. Querem convertê-los depressa em dinheiro contado e pouco lhes importa o mal porque possam passar os povos. 
O comendador é uma personagem muito mal querida pelos lavradores e por todos os que trabalham a terra. Poucas vezes é pessoalmente conhecido, porque está na Corte ou ocupa postos onde pode cobrar mais honras, receber mais mercês, obter mais pensões, procurar mais graças. $\mathrm{O}$ que se passa nos campos não lhe dói de todo. Não cuida de saber se o ano foi de abundância ou de carestia, salvo pelos preços que as suas vendas obtenham. O resultado imediato é o que lhe importa. Os municípios fazem o que podem para evitar a as saídas dos grãos para fora. Nas leis do Reino a terceira parte das colheitas deve ficar de reserva e não ser vendida para o exterior dos termos concelhios. Porém raro é que não se ouçam queixas contra os senhores proprietários ou comendadores que sem licença levam as suas rendas. $\mathrm{O}$ auto-abastecimiento desenhado nas leis é de quase impossível execução em tempos em que o mercado já manda muito ou pelo menos motiva muitos.

Às vezes, também os municípios pioram a vida dos lavradores, com encargos colectivos que estes devem pagar ou com serviços que devem prestar. Outras vezes, por causa dos foros particulares, têm que obrigar ao pagamento de velhos direitos locais. Direitos que tinham ficado agravados com a reforma dos forais novos em princípios do século XVI. Porque os ministros régios que procederam às averiguações muitas vezes confundiram velhos direitos públicos com recentes contratos privados. Muitos dos forais foram acrescentados com preceitos particulares de origem, que assim passaram a gerais. E em muitos casos, exigindo quantias que não eram desprezíveis. Portanto, aos que trabalham, pagar. Esta é a regra que há que respeitar.

Boa parte do território português não estava ainda aproveitado. Desde muito cedo se ouvem queixas de que há muitas terras incultas. E no século XVI houve algumas tentativas de aumentar a superfície dos solos cultivados. Nos cimos das serras, nas margens dos rios, em pântanos e em pauis que então foram drenados. Mas os exemplos não são muitos. Também não parece que a população tenha crescido tanto ao longo do século que impusesse uma ampliação continuada dos solos de cultivo. No decurso do século XVII nem sequer há provas de grandes e tremendas crises gerais desde a viragem do século - a população cresceu mas cresceu pouco. Houve muitas crises locais de mortalidade. Por isso a pressão demográfica não empurrou para a ocupação permanente de terras antes não aproveitadas para a agricultura. Porque um ano por outro os solos marginais, mais pobres, sempre iam sendo semeados. Mas depois havia que esperar muito tempo para que pudessem ser aproveitados de novo - a terra devia recompor-se, que ficava depressa esgotada. O que acontece é mais a defesa do que há, do que está, do que a busca de novos espaços de cultivo. Há que evitar as enxurradas dos rios, há que impedir que as areias ocupem as terras de cultivo, há que proibir 
os cortes de árvores que destroem os equilíbrios provados e permitem a acção erosiva dos elementos naturais. Isso sim.

As técnicas de trabalho da terra são ainda muito rudimentares e não muito mais desenvolvidas do que eram na Idade Média. Para a questão essencial da recomposição dos solos para cultivo de grãos a resposta comum continua a ser a divisão em folhas. Duas, três ou mais, isso depende da fertilidade do solo. Folha de grão, folha ou folhas de pousio. O mais interessante é que já se conhecem e se praticam outras formas de preparação da terra. Por exemplo, em solos férteis, sabia-se que compensava a alternância: em seguida à colheita de grãos poder-se-ia semear legumes, favas ou tremoços - o que era um bom processo, porque o estrume verde provocava a incorporação de azoto no solo - sem a perda total de rendimento que representava deixar a folha de pousio com alqueive ou em simples repouso. Porém, com excepção das Ilhas dos Açores, esta prática não se generalizou. Como fertilizante, e isto para as grandes superfícies, só se usavam as cinzas do fogo com que se limpava o restolho das terras. E mesmo isso dependia de licença municipal. Havia que roçar debaixo das árvores (aceirar), quando as havia, para que não fossem destruídas pelas chamas. Para as pequenas unidades, o esterco animal continuava a ser fundamental. Preparava-se pondo mato nos estábulos e também em alguns caminhos por onde o gado passava.

A supressão do pousio não se difundiu. Porque essa nova sementeira de substituição retirava aos gados as pastagens nas folhas que não estivessem semeadas com grãos. Gado que entrando nos pousios, contribuía um pouco para a fertilização do solo. Inclusivamente a supressão do compáscuo podia implicar o encerramento de terras. Mas como alimentar os gados? A grande questão estava em manter ou não o equilíbrio entre os cultivos e as pastagens: o compáscuo estava ainda generalizado e devidamente protegido. Os campos ficavam abertos aos gados de pastagem depois da colheita e até nova sementeira. Eliminar o pousio era pôr em causa todo o ordenamento anterior com os seus experimentados equilíbrios. Mas também estavam em causa as rendas dos dízimos. Talvez tivesse sido esta a razão mais poderosa, porque tinha implicações sociais muito fortes.

As dioceses e os cabidos (e os comendadores e quantos recebiam os dízimos) arrendavam a maior parte dos dízimos por "ramos" - assim se dizia. Nos contratos de adjudicação definiam-se as terras e os produtos a cobrar nelas que ficavam para cada arrendatário. Os grãos em geral eram entregues a um mesmo cobrador na área de um termo concelhio ou de vários termos: eram os dízimos grandes. A mudança de uma produção para outra implicava que o adjudicatário da renda dos grãos ia perder uma parte do que esperava e que o dos legumes 
(dízimos das miunças) passava a ganhá-lo - ou ao invés. A perturbação seria muito grave porque o arrendatário perdedor não se ficaria sem pleitear nos tribunais, sem requerer baixa no pagamento, sem pedir melhores condições de liquidação e por aí adiante. Bispos e cabidos não estimavam pleitos nem confusões e tudo fariam para que as coisas se mantivessem sem mudanças. Não gostavam de alterações que tivessem influência nas suas contabilidades e pacíficas arrecadações.

Ao contrário, e pelo que sabemos, a aceitação das inovações era muito fácil no interior do mesmo ramo. No que se chamava o ramo dos miúdos ou das miunças - que incidia em geral sobre os dízimos das hortas e terras de policultura intensiva - não há notícias de impedimentos às mudanças. Porque além de tudo se passar no interior do mesmo ramo, os pagamentos eram quase todos em dinheiro líquido e não nos próprios produtos. Há que suspeitar, e com boas razões, que a introdução do maíz possa ter começado pelas hortas motivo pelo que não teve oposição.

Por esta mesma razão, a substituição do centeio e dos milhos pelo maíz não criou grandes dificuldades: substituíram-se uns grãos por outros. $O$ único estorvo esteve em que o maíz não dava as palhas que muitas vezes eram requeridas por indispensáveis à formação dos estrumes. Mas sendo o adjudicatário o mesmo, o do ramo dos grãos, o aumento da produção e do seu rendimento não o aborrecia, por certo. $\mathrm{O}$ mais complicado surgia sempre quando os ramos se cruzavam uns com os outros.

Muito mais fácil seria resolver os problemas postos pelos contratos de emprazamento ou pelos de enfiteuse. Que estavam muito generalizados, muitos ainda provenientes da Idade Média. O cânon que estava consignado tinha que ser pago. Não se introduziam alterações nos prazos ou nos censos que na sua maior parte eram em três vidas ou perpétuos. Em que as duas partes contratantes sabiam o que havia que pagar e o que receber. E simplesmente, se se mudava a colheita convertia-se em dinheiro. Não era este um obstáculo decisivo. Trata-se de uma estrutura social e jurídica que não estando feita para aceitar modificações, nem sequer pequenas, se ia adaptando.

Técnicas primitivas, pois, e em tempos em que não houve pressões demográficas determinantes para mudanças profundas, ou para iniciativas de muitas novas culturas. Por isso e para a agricultura não se buscaram também muitas soluções inovadoras. Parece que o mais importante se passou nessa introdução de novas culturas, mas no interior do quadro de defesa das velhas e comprovadas formas de organização agro-pastoril. E no âmbito local, rigidamente ordenado e fiscalizado pelas oligarquias municipais. O que é contraditório com a ampliação mundial da economia na época moderna, mas os bloqueios sociais sobre a 
vida agrícola continuaram a ser dominantes até ao vendaval que virá com o liberalismo. Âmbito defensivo, conservador. Porque há notícia de introdução de novas alfaias, no início do século XVII, para roçar matos sem danificar o solo, por exemplo. Isto em baldios de pastoreio. Porque também nos instrumentos agrícolas os municípios intervinham ou podiam intervir.

Desde muito cedo as autoridades quiseram estar atentas às áreas da vida rural. Em termos defensivos. Temos bons exemplos de toda uma série de medidas para evitar a desflorestação. Porque o crescimento populacional sempre implicou uma maior exploração de lenhas e de tudo o que eram madeiras em geral. As Ordenações e as leis extravagantes do século XVI impunham a plantação de pinheiros, carvalhos, castanheiros e outras árvores. Os proprietários tinham que manifestar nas câmaras o derrube de árvores a que procediam nas suas próprias terras. Mais difícil seria fazer cumprir estas proibições nos baldios dada a sua pertença comunal. Porque muitos eram ainda esses baldios. Que muitas vezes estavam aproveitados como terras de cultura pelos que a isso tinham direito. Mas a solução de entregar o cumprimento dessa determinação à vigilância de juízes e vereadores era uma boa solução, mesmo se incompleta. Muitos desses aproveitamentos eram excepcionais, porque a maior parte dos baldios não tinham solos que pudessem "durar em lavrança por fraqueza da terra”. Assim se lê nas Ordenações Filipinas, de 1603. Mas nem sempre juízes e vereadores podiam actuar porque os baldios eram governados por parceiros que não reconheciam a autoridade do município neste caso. E nem sempre os parceiros sequer eram vizinhos do mesmo termo. São instituições diferentes, que não se sobrepõem, embora por vezes se cruzem.

Também se dá o caso de municípios que tomam para si os baldios, os quais às vezes com o tempo se confundem com os bens próprios concelhios. Casos em que toda a autoridade reside nas mãos de juízes e vereadores, que também às vezes procuram ficar com essas terras. Mas os protestos ouvem-se. Como se ouvem quando algum vizinho - normalmente alguém abastado - cerra as suas terras ou pretende impedir o pastoreio ao gado pertença da comunidade. Porque em pequenas unidades espaciais, como são as portuguesas em geral - com excepção do Alentejo e Beira Baixa - sempre os governantes dos municípios estavam em vigilância. Por isso os benefícios introduzidos, e as novas culturas, que têm que receber uma aprovação social generalizada. Não há notícia de rupturas violentas. Seja nas alfaias, no tratamento de vinhas ou olivais, seja na introdução e expansão do milho grosso.

O maíz representa uma revolução na produção agrícola do Sul da Europa e, claro está, da portuguesa. Discute-se, sem se chegar a um consenso, a data da sua introdução em Portugal. E também a sua origem geográfica. Porque 
as descrições e referências documentais não dão para decidir quando se fala de maíz ou de sorgos africanos, se é que estes também foram aclimatados. Fosse como fosse, o certo é que o centeio tinha um velho companheiro no milho miúdo - com que se fazia o pão meado. E que ao novo grão se deu o nome de milho. Donde uma dificuldade acrescida. Mas o maíz faz a sua entrada na paisagem agrícola de Portugal no século XVI. Parece certo que o semearam primeiro nas hortas, em terras húmidas e de regadio. As notícias falam da sua introdução pelos vales do Mondego e do Douro. Nas hortas da região de Coimbra e no Algarve já o temos por finais do século XVI. No Norte vão subsistir os milhos miúdos. E mesmo em Lisboa vemos o milho grosso entrar na dieta alimentar dos pobres. Porque o trigo se mantém insubstituível nas mesas dos ricos, que não dispensavam o bom pão branco.

No Sul, no Alentejo e no Algarve, de clima mediterrâneo, mais seco, o maíz não alcançou uma grande importância. O trigo continuou a ser, sem dúvida, o mais comum dos cereais. A que se segue o centeio, que se semeia nos solos mais pobres, que é mais resistente às irregularidade do tempo. Que venham estiagens ou demasiadas águas e alguma produção se achará, residual embora. Mas nas hortas, com o regadio, o maíz dá-se bem e tem uma elevada produtividade. No Algarve estimam-no e comem-no em papas, não em pão. Moído em mós manuais, porque não seria grande a quantidade de que cada produtor disporia. Já era muito popular no século XVIII. No entanto, só se começa a encontrar o maíz individualizado nos dízimos por volta de 1630 .

No Alentejo o maíz quase se não implantou? Terra de trigo, de grandes propriedade, dominam as culturas extensivas e de sequeiro. E o pão de trigo e o de centeio é o comum na dieta alimentar. Mas há que suspeitar que nos pequenos espaços de policultura deixados para garantir a sobrevivência dos trabalhadores, entre os quais os escravos, o maíz não seria desprezado. Para consumo desses pequenos núcleos, talvez também em papas.

Tampouco na Estremadura e Ribatejo há sinais de que o maíz tivesse ganho uma grande importância. Mas não há que esquecer a proximidade de Lisboa e as muitas hortas para provimento dos moradores nas vilas e povoados próximos do Tejo. $\mathrm{O}$ facto de que cedo se fale de boroa de milho no mercado da capital faz-nos suspeitar de que se cultivava comummente.

Nas Beiras, como por toda a parte, o grão dos pobres é o centeio. Só o maíz é que vai modificar as coisas. Até 1623 é ainda o centeio que predomina, mas depois desta data não ganhará mais. Os dois apresentam-se em relativo equilíbrio até que por 1680 os milhos mostrarão uma produção de maior volume. O seu triunfo é inegável nas terras capazes de regadio. E o seu crescimento foi sempre 
à custa do centeio. O que se compreende. O maíz tem um ciclo vegetativo mais curto, tão só de cinco meses - o trigo e o centeio necessitam de nove meses. No resto do ano aproveitam-se os campos com prados ou com outras produções de primores. É um aproveitamento notável para os campos de policultura. E além do mais, a planta do maíz é de grande proveito para alimentar o gado, sobretudo o vacum.

Não é precoce a revolução do maíz nas Beiras. Tampouco terá sido em Entre Douro e Minho. Aparece nos dízimos da abadia beneditina de Tibães só pelos anos de 1630. Mas desde um pouco antes, por 1625, já se assinalava como decisivo para a alimentação das povoações regionais do Norte. A humidade natural da região, aliada à policultura intensiva e à pequena propriedade favorecem-no. Ao maíz amparavam-se os feijoeiros, poupando espaço e autorizando uma produção mais. Mesmo se a introdução não foi muito cedo, depressa se tornou muito popular.

A cultura do maíz expandiu-se e o seu consumo generalizou-se durante o século XVII. Entre os pobres, há que repeti-lo. Que com menos trabalho podiam começar mais cedo as colheitas e inclusivamente aproveitar as maçarocas ainda não sazonadas e comê-las. E guardar os caules e as folhas para os gados. Mas tudo isto se passou mais de um século depois da chegada dos europeus à América. Inclusivamente, o lunário perpétuo de Gaspar Cardoso de Sequeira, de 1612, intitulado Thesouro de Prudentes, não traz ainda referida a semeadura do maíz, nem sequer se nomeiam os milhos: como grãos figuram o trigo, o centeio e a cevada. E tão só.

A alta produtividade do maíz ajuda a compreender por que foi adoptado por todas as partes onde as condições naturais o permitiram - ou facilitaram. Sem substituir o trigo, deixando ao centeio as terras piores ou sem possibilidades de rega. Apesar das notórias vantagens que se lhe apontam, o maíz teve que vencer dificuldades sociais que o encerramento dos campos implicava. Mas a sua grande produtividade, e o facto de que se instalou primeiro em terras de regadio e de policultura intensiva, já cerradas, ajudaram-no a vencer os obstáculos de uma estrutura agrária pouco flexível, que suportava mal qualquer mudança.

Há que suspeitar que o generalização do maíz se relaciona com os ricos mosteiros do Norte - sobretudo os beneditinos. Que gozavam de jurisdições senhoriais plenas sobre as suas terras (os coutos), em que os municípios e os senhorios vizinhos não podiam interferir. A introdução do novo cereal, como o tapar das suas áreas de plantação eram da responsabilidade do juiz e dos vereadores dos coutos, muito de perto vigiados pelas comunidades religiosas que detinham os senhorios. Que escolhiam as culturas mais rentáveis, sem outras considerações mais. Juízes e vereadores dos coutos não recusavam 
ou discutiam a autoridade dos monges. E o mesmo pode ter-se passado nas grandes propriedades dos senhorios aristocráticos. Que tinham com que investir e podiam evitar as imposições colectivas ou não dar atenção aos protestos provocados pelos seus incumprimentos.

Muitas mais notícias temos do esforço dos lavradores para melhorar as vinhas. E esse é um dado relevante ocorrido nas primeiras quatro décadas do século XVII. Depois, com a desorganização provocada pelos recrutamentos militares e com os problemas de falta de mão-de-obra por causa da guerra da Restauração, instalou-se uma grave depressão. Guerra muito demorada na Península (1641-1667). Mas também guerra muito longa no ultramar: em que se perdeu e recobrou o Nordeste do Brasil; em que se perdeu o posto de resgate de São Jorge da Mina donde vinha ouro; em que se foram para os Holandeses boa parte das possessões asiáticas, sobretudo as do Sudeste e Ceilão. Guerra em que o território da Península, nas regiões de fronteira, ficou muito arruinado. Acima de tudo, pelas razías das tropas, pelos incêndios, pelos roubos de gado. Inclusivamente no Sul difundiram-se pestes tremendas (1649-1650).

Estes e muitos mais efeitos confluíram a desencadear uma grave crise que também foi financeira. Como a mais notada das razões para essa situação gravosa, de 1670, aponta-se em especial a escassez da moeda de prata. Que antes da guerra vinha das Índias de Castela, por negócios em Sevilha ou na raia seca, ou por contrabando. Intentam-se políticas com que se procura responder à crise, inclusivamente com o aumento das exportações de vinho. Porque o século XVII tinha sido um tempo de muito trabalho nesse produto. O que começara no século anterior. Mas cujos resultados então ficavam muito visíveis. E era o que havia para vender ao exterior.

Nas exportações para o Oriente e para as Américas sempre ia um importante contingente de vinhos. E os mercados, se às vezes não eram muito exigentes, em geral foram impondo uma melhoria nas qualidades dos que saíam do Reino. $\mathrm{E}$ o mesmo ocorreu com os espaços urbanos que dinamizaram a procura. A protecção às vinhas com autorizações relativamente fáceis de tapar terras - ao contrário do que sucedia com os demais produtos agrícolas - também ajudou a motivar os cidadãos possuidores a investir nessa cultura. E assim também os mercadores que de algum modo pretendiam garantir os seus haveres ou aproximar-se das oligarquias locais.

O status de dono de vinhas era muito mais relevante do que o de simples mercador de tenda ou mesmo homem de negócios por atacado. Isto implica um arranjo de pequenas propriedades, muitas das quais só constituídas por vinhas, sem outras culturas à mistura. Muitos cristãos novos escolhem esta via para se afastarem da ignomínia de não ter bens de raiz nos povos onde vivem - mas 
investindo num produto comercial. Mas são as próprias oligarquias tradicionais as que começam a aplicar os seus capitais aos vinhedos.

A diminuição dos negócios por causa da crise e das guerras no Atlântico provocou uma ruralização dos interesses pelo que os investimentos no vinho se tornaram muito mais atractivos. Os preços dos vinhos seriam compensadores. Assim aconteceu com o patriciado urbano do Porto, desde fins do século XVI, o que provocou o alargamento da área de vinha nas encostas do Douro. Vinho que se converterá no vinho do Porto no século XVIII. Vinho esse que desde muito cedo começa a ser preparado, ou seja melhorado por junção de outros vinhos e de aguardentes. Outras regiões vinícolas começam a esboçar-se. Era uma especialização necessária, pois o desenvolvimento da vinha é um fenómeno de todo o Mundo Mediterrâneo pelo que a concorrência aumenta. Mas também é enorme o seu consumo. A Grande Armada de 1588 transportava nada menos que 14170 tonéis de vinho.

O vinho vai ser produzido em todas as partes onde haja condições climáticas para isso. E por toda a parte vai levantar-se a questão do compáscuo. Os campos abertos possibilitam a entrada dos gados, mas se neles estavam vinhas estas perdiam-se porque os animais comiam as uvas. Pelo que muitos queriam cerrar os campos. As câmaras vão deixando que alguns tapem e sobretudo vão impondo outras defesas mais tradicionais, mas menos eficazes, impondo o pagamento de multas aos donos dos gados prevaricadores.

No Norte há quem use apoiar as vides em árvores, que muitas vezes marcam os extremos das terras. Não é o melhor este vinho que se faz destas vinhas ditas de "enforcado". Seria bebida de consumo local, não tendo qualidade para enfrentar as longas temporadas nos navios. Nem sequer para satisfazer paladares mais exigentes: os monges de São Bento de Tibães que em muito contribuíram para o aumento da produção vinícola compravam bons vinhos para a sua mesa. O acidulado "verde" das suas terras davam-no aos seus muitos servidores, ou vendiam-no. Vides e árvores andam de par a par: junto com a preocupação pelo aumento do plantio de árvores, aproveitava-se para impulsionar as novas vides que abraçam apoios vegetais. Em geral, sem sair dos espaços de cultivo tradicionais que assim acolhem novos produtos. Às vezes acontece que estas novas vinhas vão ocupar partes de baldios ou de incultos. Em geral, respeitam-se os equilíbrios socialmente arreigados. Que exigiam imobilidade nas práticas, para que não se introduzissem novidades que fossem prejudicar alguém ou a quase todos, pensava-se.

No Sul, a expansão de vides e oliveiras ocorreu não muito longe dos povoados. Porque necessitam de muitos cuidados e de muita mão-de-obra, mas esta só é necessária em tempos de vindima ou apanha. E nesses momentos 
há que assalariar gente dos povoados vizinhos. Não assim no Norte, muito mais ocupado, e onde as explorações são mais pequenas, em geral. Não era necessário assalariar muita gente para fazer uma pipa, ou por aí, bastava a família.

Este é um fenómeno que também ocorre pelo que toca às oliveiras. A procura de azeite nos territórios ultramarinos sobe, pois não havia substituto para ele. As cargas para o Oriente e para o Brasil incluem sempre muito azeite, para consumo durante a viagem e para venda no porto de chegada. Os preços compensavam, pelo que os capitais se orientam nessa aplicação.

Tal como com o vinho, os proprietários de terras investem nas oliveiras, e isto por todas as partes do Reino. Nas do Sul, em que desde sempre é uma cultura muito estimada, até à região de Entre-Douro e Minho e em Trás-os-Montes, onde novas plantações são muito notadas por tardias. Inclusivamente os grandes mosteiros põem oliveiras por todas as partes que podem, e sabemos de novos lagares que os monges fazem construir. A oliveira é plantada promiscuamente com outras espécies: não parece que haja numerosos novos olivais - nem sequer no Sul Mediterrâneo. Crescem as oliveiras por toda a parte onde o clima as aceita, porque eles não suportam altitudes acima dos $700 \mathrm{~m}$, nem a proximidade de ventos mareiros. Mas nem sempre é a oliveira que se planta. No Sul prefere-se o mais rústico e mais forte zambujeiro, que depois há que enxertar com cuidado, para que se obtenham boas azeitonas. Que as há de muitas qualidades e sabores, de mais ou menos resistência ao tempo depois de curadas. Azeitonas que se levavam também para as lonjuras do império.

A reposição de árvores ou a arborização de regiões escalvadas é política muito comum no século XVII. Como é constante a defesa das árvores de fruto, que em certas regiões, como no Sul (Algarve), constitui a base da economia rural. Figos, amêndoas e alfarrobas exportam-se para o Norte da Europa e também para o Mediterrâneo. Mas em especial, e um pouco por toda a parte, começa a expandir-se a laranjeira, sobretudo a da laranja doce da China, de onde era originária. Cultura de horta, que necessita de muita água, os ricos proprietários vão plantá-la onde o solo e a exposição solar permitem bons frutos. A laranjeira não punha dificuldades às pastagens, porque os pomares estavam já devidamente vigiados, sem que fosse obrigatório manter dentro deles as mesmas espécies. Cultura para exportação, porque a procura estava mostrando que havia consumidores para as laranjas no Norte da Europa. Era presente muito apreciado em Londres, que se enviava à portuguesa rainha D. Catarina.

Inovações, continuações. Com bloqueios continuados de uma estrutura social e política que mal aceitava as transformações que o aumento da produção exigia. Pelo que a introdução de novidades se viu limitada e retardada. Mas também no 
interior das terras de policultura intensiva algumas coisas foram ocorrendo que fogem à observação. Será o caso da batata? Não há, para já, resposta possível.

É facto que na região de Coimbra, em terras de senhorio do opulentíssimo Mosteiro de Santa Cruz, no couto de Quiaios, se tinham semeado batatas em 1643. Os vizinhos recusavam-se a pagar a sétima parte que deviam aos cónegos pelos direitos do foral. Os religiosos só queriam o pagamento, não discutiam o produto. Pelo que há que supor que o solo utilizado teria sido o marginal, onde não se faziam outras culturas, presumivelmente as areias da praia próxima. E tratava-se de uma grande quantidade: a sétima parte exigida era de 250 fangas. O que conduz a uma produção muito interessante. Mas qual era a batata é que não sabemos. No século XVI semeava-se já nos Açores a raiz que se chama ainda hoje de batata. Que não é o tubérculo que se generalizou muito mais tarde como batata redonda ou batata inglesa - que deveria ser dita americana.

De outra cultura temos notícia, e que também se desenvolve em solos arenosos ou em terras sem outra utilização, que é o sumagre. Arbusto cujas folhas são ricas em tanino, tinha uso na preparação dos couros. Encontramo-lo no Norte como no Algarve no século XVII. Outras produções podem ter sido experimentadas, sem que a sua difusão acontecesse. Sobretudo em solos marginais, incultos e por isso não provocando alterações e pleitos judiciais no pagamento tradicional dos dízimos ou dos direitos senhoriais.

Estas não seriam as únicas tentativas para aliviar uns tempos de tanto e tão duro trabalho, aumentando os rendimentos dos lavradores com culturas novas, de boa exportação ou de fácil aceitação para o consumo. Mas de facto para mudar as coisas, havia que combinar a diversificação das culturas com a intensificação dos cultivos. O que só os muito poderosos podiam ensaiar. Contra os pequenos, que esses tinham que se valer de alguma defesa na protecção colectiva. Eram esses velhos interesses os que aí estavam, vigilantes, para impedir tudo o que fosse inovação contrária aos equilíbrios provados. Talvez por isso a agricultura do século XVII não conheceu o desenvolvimento para que estaria preparada tecnicamente. Talvez.

\section{Bibliografia sumária}

Almeida, Luís Ferrand de, "A propósito do milho "marroco" em Portugal nos séculos XVI-XVIII”, in Revista Portuguesa de História, Coimbra, Faculdade de Letras, 1992.

Amorim, Inês, O mosteiro de Grijó. Senhorio e propriedade: 1560-1720 (formação, estrutura e exploração do seu domínio), Braga, Ul-Vária, 1997. 
Godinho, Vitorino Magalhães, Os Descobrimentos e a Economia Mundial. $2^{a}$ ed., Lisboa, Presença, 1982-1983.

Magalhães, Joaquim Romero, "As estruturas da produção agrícola e pastoril”, in José Mattoso (direc.), História de Portugal, vol. III, coord. Joaquim Romero Magalhães, $O$ alvorecer da Modernidade, Lisboa, Círculo de Leitores, 1993.

Magalhães, Joaquim Romero, O Algarve económico, 1600-1773, Lisboa: Editorial Estampa, 1988.

Maia, Fernanda Paula Sousa, O mosteiro de Bustelo: propriedade e produção agrícola no Antigo Regime (1628-1670 e 1710-1821), Porto, Universidade Portucalense, 1991.

Meneses, Avelino de Freitas de, "A produção", in Joel Serrão e A. H de Oliveira Marques (direc.), Nova História de Portugal, vol. VII, Lisboa, Editorial Presença, 2001.

Monteiro, Isilda Braga da Costa, A administração jesuíta do mosteiro de Pedroso de 1560 aos finais do século XVII, Porto, Universidade Portucalense, 1993.

Neto, M. Margarida Sobral, "Introdução e expansão da cultura da batata na região de Coimbra (sécs. XVII-XIX)", in Revista Portuguesa de História, t. XXIX, Coimbra, Faculdade de Letras, 1994.

Neto, M. Margarida Sobral, Terra e conflito. Região de Coimbra. 1700-1834, Viseu, Palimage Editores, 1997.

Oliveira, António de, A vida económica e social de Coimbra de 1537 a 1640, Coimbra, Faculdade de Letras, 1971/1972.

Oliveira, Aurélio de, “Contabilidades monásticas e produção agrícola durante o Antigo Regime. Os dízimos do Mosteiro de Santo Tirso 1626-1821", in Actas do Colóquio de História Local e Regional, Santo Tirso, 1982.

Oliveira, Aurélio de, "Mercados a Norte do Douro. Algumas considerações sobre a história dos preços em Portugal e a importância dos mercados regionais (séculos XVII-XVIII)", in Revista da Faculdade de Letras, Porto, 1985.

Oliveira, Aurélio de, "Níveis de produção vinícola no Entre Douro e Minho 1629-1822", in 1 'Jornadas de Estudo Norte de Portugal / Aquitânia, Porto, 1986.

Oliveira, Aurélio de, "Os vinhos do Porto: 1600-1700 (Política e administração municipais)", in Douro - Estudos \& Documentos vol. I (3). Porto: 1997.

Oliveira, Aurélio de, A abadia de Tibães 1630/80 - 1813. Propriedade, exploração e produção agrícolas no Vale do Cávado durante o Antigo Regime. Porto: Faculdade de Letras, 1979.

Oliveira, Aurélio de, A abadia de Tibães e o seu domínio (1630-1680). Estudo social e económico, Porto, Faculdade de Letras, 1974. 
Oliveira, João Nunes de, “'Diário’ de um pároco da vila de Santa Comba Dão ao tempo da dinastia filipina”, in Revista de História Económica e Social, Lisboa: $2^{\mathrm{a}}$ série, $\mathrm{n}^{\mathrm{o}} 3$.

Oliveira, João Nunes de, A produção agrícola de Viseu entre 1550 e 1700, Viseu, Câmara Municipal, 1990.

Rau, Virgínia, “A grande exploração agrária em Portugal a partir de fins da Idade Média" in Estudos de História Económica, Lisboa, Ática, 1961.

Ribeiro, Orlando, "Significado ecológico, expansão e declínio da oliveira em Portugal", in Boletim do IAPO, ano VII, n 2, Lisboa, 1979.

Ribeiro, Orlando, Lautensach, Hermann e Daveau, Suzanne, Geografia de Portugal. IV. A vida económica e social, Lisboa, Edições João Sá da Costa, 1991.

Sequeira, Gaspar Cardoso de, Thesouro de Prudentes, Coimbra, Impressão da Viuva de Manoel Carvalho, impressor da Universidade, 1664.

Serrão, José Vicente, “A agricultura e a terra”, in José Mattoso (direc.), História de Portugal, vol. IV, coord. de António Manuel Hespanha, O Antigo Regime, Lisboa, Círculo de Leitores, 1993.

Silva, L. A. Rebello da Silva, Memoria sobre a população e a agricultura de Portugal desde a fundação da Monarchia até 1865 Parte I (de 1097-1640), Lisboa, Imprensa Nacional, 1868. 